\title{
CURIOSIDADES MATEMÁTICAS NAS ARITMÉTICAS DA SÉRIE ORDEM E PROGRESSO
}

\author{
CURIOSIDADES MATEMÁTICAS EN LAS ARITMÉTICAS DE LA SERIE \\ ORDEN Y PROGRESO
}

\section{MATHEMATICAL CURIOSITIES IN THE ARITHMETIC OF THE ORDER AND PROGRESS SERIES}

\author{
Malcus Cassiano KUHN ${ }^{1}$ \\ Arno BAYER ${ }^{2}$
}

RESUMO: O artigo tem por objetivo fazer um resgate de curiosidades matemáticas presentes nas aritméticas da série Ordem e Progresso, editadas pela Igreja Evangélica Luterana do Brasil, por meio da Casa Publicadora Concórdia de Porto Alegre, na década de 1930, para suas escolas paroquiais no Rio Grande do Sul. Baseando-se no referencial da história cultural, analisaram-se a Primeira Aritmética e a Terceira Arithmetica da série Ordem e Progresso, identificando-se curiosidades envolvendo: construção do significado de número até 10; contas orais com as quatro operações elementares com números naturais até 100; procedimentos para decorar as tabuadas de multiplicar e dividir; informações sobre unidades de medidas do contexto dos alunos; relações entre as antigas medidas brasileiras e as medidas do sistema métrico; estudo da regra de três pela regra da dedução; cálculo do volume aproximado de um tronco de cone, de forma prática; determinação de números quadrados e da raiz quadrada fazendo associações com geometria e álgebra. Embora algumas dessas curiosidades estejam alicerçadas no método de ensino intuitivo, as mesmas ainda refletem a tradição pedagógica da memorização.

PALAVRAS-CHAVE: História da educação matemática. Curiosidades matemáticas. Série ordem e progresso. Ensino da matemática. escolas paroquiais luteranas gaúchas.

RESUMEN: El artículo tiene por objetivo hacer un rescate de curiosidades matemáticas presentes en las aritméticas de la serie Orden y Progreso, editadas por la Iglesia Evangélica Luterana de Brasil, a través de la Casa Publicadora Concordia de Porto Alegre, en la década de 1930, para sus escuelas parroquiales en Rio Grande do Sul. Basándose en el referencial de la historia cultural, se analizaron la Primera Aritmética y la Tercera Arithmetica de la serie Orden y Progreso, identificándose curiosidades envolviendo: construcción del significado de número hasta 10; cuentas orales con las cuatro operaciones elementales con números naturales hasta 100; procedimientos para

${ }^{1}$ Instituto Federal de Educação, Ciência e Tecnologia Sul-rio-grandense (IFSul), Lajeado - RS - Brasil. Professor Doutor em Ensino de Ciências e Matemática pela Universidade Luterana do Brasil - ULBRA. Membro do Grupo de Pesquisas sobre Formação de Professores de Matemática - GPFPMat. E-mail: malcuskuhn@ifsul.edu.br

${ }^{2}$ Universidade Luterana do Brasil (ULBRA), RS - Brasil. Professor e Pesquisador do Programa de PósGraduação em Ensino de Ciências e Matemática - PPGECIM. Doutor em Ciências da Educação pela Universidade Pontifícia de Salamanca - Espanha. Coordenador do Grupo de Pesquisas sobre Formação de Professores de Matemática - GPFPMat. E-mail: bayer@ulbra.br 
decorar las tablas de multiplicar y dividir; información sobre unidades de medidas del contexto de los alumnos; las relaciones entre las antiguas medidas brasileñas y las medidas del sistema métrico; el estudio de la regla de tres por la regla de la deducción; el cálculo del volumen aproximado de un tronco de cono, de forma práctica; la determinación de números cuadrados y de la raíz cuadrada haciendo asociaciones con geometría y álgebra. Aunque algunas de esas curiosidades están basadas en el método de enseñanza intuitiva, las mismas todavía reflejan la tradición pedagógica de la memorización.

PALABRAS CLAVE: Historia de la educación matemática. Curiosidades matemáticas. Serie orden y progreso. Enseñanza de las matemáticas. Escuelas parroquiales luteranas gauchas.

ABSTRACT: The article aims to make a rescue of mathematical curiosities present in the arithmetic of the Order and Progress series, edited by the Evangelical Lutheran Church of Brazil, through Concordia Publishing House of Porto Alegre, in the 1930s, for its parochial schools in Rio Grande do Sul. Based on the reference of the cultural history, were analyzed the First Arithmetic and the Third Arithmetic of the Order and Progress series, identifying curiosities involving: building of the meaning the number until 10; oral counts with the four elementary operations with natural numbers until 100; procedures to decorate the multiplication table of multiply and divide; information about units of measures of the students context; relations between the old Brazilian measures and measures of the metric system; study of three rule by the rule of deduction; calculating of the volume of a cone frustum of practice and approximate way; determination of square numbers and of the square root making associations with geometry and algebra. Although some of these curiosities are grounded in the intuitive teaching method, they still reflect the pedagogical tradition of memorization.

KEYWORDS: History of the mathematics education. Mathematical curiosities. Order and progress series. Mathematics teaching. Gaucho lutheran parochial schools.

\section{Introdução}

O presente artigo faz um resgate das curiosidades matemáticas encontradas nas edições da Primeira Aritmética e da Terceira Arithmetica, integrantes da série Ordem e Progresso e editadas pela Igreja Evangélica Luterana do Brasil - IELB, por meio da Casa Publicadora Concórdia de Porto Alegre, na década de 1930, para suas escolas paroquiais no Rio Grande do Sul - RS. Trata-se de um recorte de tese de doutorado, complementado por pesquisas realizadas durante o estágio Pós-doutoral no Programa de Pós-Graduação.

Como a temática investigada se insere na História da Educação Matemática no RS e está relacionada com o movimento migratório para esse estado, é preciso destacar os trabalhos de Kreutz (1991, 1994, 2008), Rambo (1994, 1996), Lemke (2001), Arendt (2005) e Weiduschadt (2007, 2012), no âmbito da História da Educação no RS, e as 
pesquisas de Mauro (2005), Kreutz e Arendt (2007), Wanderer (2007), Silva (2015), Kuhn (2015) e Britto (2016), relacionadas com a História da Educação Matemática no estado gaúcho.

Fundamentando-se no referencial da história cultural, realiza-se a análise documental da série Ordem e Progresso, a qual contém três aritméticas voltadas para o ensino da Matemática nos primeiros anos de escolarização. $\mathrm{O}$ estudo se restringe a essa coleção de livros de aritmética pois foi a primeira editada e publicada pela IELB, para suas escolas paroquiais no século passado. No Instituto Histórico da IELB, em Porto Alegre, localizaram-se a Primeira e a Terceira Aritmética da série Ordem e Progresso. Ressalta-se que ainda não foi localizada a Segunda Aritmética dessa série. Precedendo a discussão de curiosidades matemáticas encontradas nas duas aritméticas da série Ordem e Progresso, aborda-se o referencial teórico-metodológico da história cultural.

\section{A histórica cultural como referencial teórico-metodológico}

A história cultural - Kulturgeschichte - se ocupa com a pesquisa e representação de determinada cultura em dado período e lugar - neste estudo, primeira metade do século XX e escolas paroquiais luteranas no RS -, como: relações familiares, língua, tradições, religião, arte e algumas ciências. A história cultural se interessa pelos sujeitos produtores e receptores da cultura, o que abarca a função social dos intelectuais - como os editores e autores dos livros de aritmética das séries Ordem e Progresso - e o público receptor como os professores e alunos das escolas paroquiais luteranas no RS -. Barros (2003, p. 148), complementa que "[...] agências de produção e difusão cultural também se encontram no âmbito institucional: os sistemas educativos, a imprensa, os meios de comunicação, as organizações socioculturais e religiosas".

Um dos principais estudiosos sobre a história cultural é o do francês Roger Chartier, cuja contribuição está na elaboração das noções complementares de "práticas" e "representações". De acordo com este horizonte teórico, a cultura poderia ser examinada no âmbito produzido pela relação interativa entre estes dois polos. Conforme Barros (2003, p. 157), “[...] tanto os objetos culturais seriam produzidos entre práticas e representações, como os sujeitos produtores e receptores da cultura circulariam entre estes dois polos, correspondendo, respectivamente, aos modos de fazer e aos modos de ver". De acordo com Chartier (1990), as noções complementares de práticas e representações são úteis para examinar os objetos culturais produzidos, os sujeitos produtores e 
receptores de cultura, os processos que envolvem a produção e a difusão cultural, os sistemas que dão suporte a estes processos e sujeitos e as normas a que se conformam as sociedades através da consolidação de seus costumes. "As práticas e representações são sempre resultado de determinadas motivações e necessidades sociais" (BARROS, 2003, p. 161).

$\mathrm{Na}$ análise das aritméticas da série Ordem e Progresso, editadas pela IELB, por meio da Casa Publicadora Concórdia, para as escolas paroquiais luteranas gaúchas do século XX, é preciso considerar que, de acordo com Chartier (1990), as práticas culturais que aparecem na construção de um livro são tanto de ordem autoral (modos de escrever, pensar ou expor o que será escrito), como editoriais (reunir o que foi escrito para constituílo em livro), ou ainda artesanais (a construção do livro na sua materialidade). Da mesma forma, quando um autor se põe a escrever um livro, ele se conforma a determinadas representações do que deve ser um livro, a certas representações concernentes aos temas por ele desenvolvidos. Esse autor também poderá se tornar criador de novas representações, que encontrarão no devido tempo uma ressonância maior ou menor no circuito do leitor ou na sociedade mais ampla. A leitura e o uso de um livro também gera práticas criadoras, podendo produzir concomitantemente práticas sociais. Essa leitura e uso poderão ser individuais ou coletivos, e o seu conteúdo poderá ser imposto ou rediscutido. A partir da leitura e difusão do livro, poderão ser geradas inúmeras representações novas sobre os temas que o atravessam, que em alguns casos poderão passar a fazer parte das representações coletivas. Para Chartier (1990, p. 17), a história cultural tem por principal objeto identificar o modo como "[...] em diferentes lugares e momentos uma determinada realidade cultural é construída, pensada, dada a ler, por diferentes grupos sociais", o que está fortemente relacionado à noção de representação.

Ainda segundo Chartier (1990), uma questão desafiadora para a história cultural é o uso que as pessoas fazem dos objetos que lhes são distribuídos ou modelos que lhes são impostos, uma vez que há sempre uma prática diferenciada na "apropriação" dos objetos colocados em circulação. Nessa perspectiva, pode-se dizer que a imprensa pedagógica, aqui representada pelas aritméticas da série Ordem, foi um veículo para circulação de ideias que traduziam valores e comportamentos que se desejava ensinar, sendo postas em convergência com outras estratégias políticas e culturais no RS.

\section{O contexto para edição dos livros de aritmética da série Ordem e Progresso}


Em 1847, um grupo de imigrantes luteranos alemães da Saxônia fundou no estado de Missouri - Estados Unidos -, o Sínodo Evangélico Luterano Alemão de Missouri, Ohio e Outros Estados, atualmente Igreja Luterana - Sínodo de Missouri (WARTH, 1979). Em 1900, os missourianos iniciaram missão nas colônias alemãs gaúchas, fundando congregações religiosas e escolas paroquiais. De acordo com Kuhn (2015), tais escolas estavam inseridas num projeto missionário e comunitário que buscava ensinar a língua materna, a Matemática, valores culturais, sociais e, principalmente, religiosos. Se a escola formasse o ser humano com postura ética e moral exemplar, este poderia promover transformações sólidas em seu contexto social e seria um verdadeiro colaborador na seara de Deus e para o governo do mundo.

O Sínodo de Missouri também tinha uma preocupação acentuada em relação aos recursos didáticos usados nas escolas paroquiais, pois esses materiais eram escassos e a dificuldade era grande em manter um ensino planificado e organizado. De acordo com Weiduschadt (2007, p. 41), “[...] os livros usados nas escolas paroquiais e utilizados pelos alunos foram produzidos pelas instituições religiosas com objetivo de formar e moldar as condutas e as práticas ao fazer a escolarização das comunidades". Assim, por meio de livros escolares, como as aritméticas da série Ordem e Progresso, as escolas paroquiais luteranas gaúchas buscaram desenvolver uma educação integral cristã em todas as disciplinas. Nessas escolas, conforme Lemke (2001, p. 80), “[...] o ensino da Palavra de Deus, através da Bíblia, ficava em primeiro lugar, as demais disciplinas não eram menosprezadas, mas complementavam a educação para servir no mundo".

Conforme estudos realizados por Kuhn (2015), o ensino da Matemática, nos primeiros anos de escolarização nas escolas paroquiais luteranas gaúchas, priorizava os números naturais, os sistemas de medidas, as frações ordinárias e decimais, complementando-se com a matemática comercial e financeira e a geometria. $\mathrm{O}$ ensino da Matemática deveria acontecer de forma prática e articulada com as necessidades dos futuros agricultores, observando-se a doutrina luterana.

Os primeiros trinta anos de existência das escolas paroquiais luteranas no RS foram marcados pela carência de materiais didáticos e pela progressiva adoção dos quatro manuais de Büchler, tanto em alemão, quanto em português, para as aulas de Matemática.

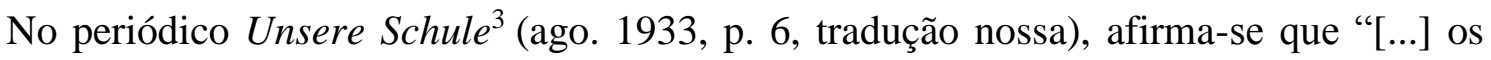

\footnotetext{
${ }^{3}$ Na década de 1930, a IELB começou a publicar um periódico dirigido às escolas paroquiais, chamado Unsere Schule (Nossa Escola), predominando informações e artigos pedagógicos escritos em alemão.
} 
livros de aritmética de Büchler (editora Rotermund) ${ }^{4}$ são usados na maioria das nossas escolas e que a mesma editora lançou recentemente um novo manual: meu livro de contas, por W. Nast e L. Tochtrop". Porém, na mesma edição, este manual é analisado criticamente, apontando-se a necessidade de uma edição com princípios morais e educacionais luteranos, com uso de princípios pedagógicos modernos e adaptada às condições nacionais, pois o processo de nacionalização do ensino estava em curso.

A representação das figuras da capa do $1^{\circ}$ e $2^{\circ}$ livros pode ser confundida com figuras malignas e assustar as crianças. Mas há coisas piores: a história dos 10 negrinhos (p. 20 do $1^{\circ}$ livro) pode parecer inofensiva, mas, fazendo-se uma inspeção mais cautelosa, você verá algo que não é apropriado para nossos filhos, pois a instrução matemática também serve a educação. Você pode ver na imagem e nas palavras, que um negrinho se enforca, outro se deixa atacar por uma bruxa, um terceiro e um quarto se perderam na cerveja e no vinho. Também rejeitamos as tarefas de cálculo para os alunos com resultados da loteria (p. 17 e 76 do $2^{\circ}$ livro). [...] Quanto à terceira exigência de que um livro de cálculo deve estar adaptado às condições nacionais, somos da opinião de que a instrução matemática deve ser feita na língua nacional. Embora, nossas crianças da colônia compreendam nada de português, em tais casos, o professor pode interferir com a instrução e explicação no idioma alemão. Se darmos para nossas crianças de origem alemã, aulas de língua alemã, ensinarmos assuntos religiosos na língua materna e ensiná-los a cantar canções alemãs, ensinar matemática e outras disciplinas reais na língua nacional, estaremos preservando o germanismo e nenhum dano será causado, pois apenas estaremos fazendo nossa obrigação de contruir um Estado melhor (UNSERE SCHULE, 1933, p. 6, tradução nossa).

Por isso, o Sínodo de Missouri começou a produzir seus próprios livros de aritmética na década de 1930. A Casa Publicadora Concórdia ${ }^{5}$ de Porto Alegre editou e publicou o material didático específico para as escolas paroquiais luteranas. Para as aulas de Matemática, foram publicadas duas séries: a série Ordem e Progresso, lançada na década de 1930, e a série Concórdia, lançada na década de 1940. De acordo com Lemke (2001, p. 79), “[...] a série Ordem e Progresso é uma coleção constituída por livros de leitura, história bíblica e matemática em que os próprios textos de alfabetização e cálculo trazem ensinamentos bíblicos e contém temas de cunho moral e cristão”.

\footnotetext{
${ }^{4}$ A editora Rotermund, de São Leopoldo, editava e publicava o material didático relacionado ao Sínodo Rio-Grandense (Igreja Evangélica de Confissão Luterana no Brasil - IECLB).

${ }^{5}$ Fundada em 1923, atuava na edição de livros e de periódicos relacionados à literatura religiosa e escolar da IELB. Foi a primeira e a única redatora da IELB, existente até os dias atuais. Antes de sua fundação, os livros e os periódicos eram impressos pela Concordia Publishing House, nos Estados Unidos, e enviados ao Brasil.
} 
A Primeira Aritmética da série Ordem e Progresso, [193-] possui 64 páginas, não apresenta sumário e tem como autor o professor paroquial Frederico Strelow (18881946), que se formou na primeira turma de professores no Seminário Concórdia ${ }^{6}$ de Porto Alegre, em abril de 1912. Strelow também foi redator do periódico Unsere Schule. A Terceira Arithmetica da série Ordem e Progresso, [193-] tem 143 páginas, não possui sumário, nem autoria declarada. Não se tem a informação sobre a quantidade de exemplares publicados em cada edição dessas aritméticas, pois tal dado não foi encontrado. Na década de 1940, a série Ordem e Progresso foi substituída, gradativamente, pela série Concórdia. Ressalta-se que as edições da Primeira Aritmética das duas séries são diferentes, enquanto as duas edições da Terceira Aritmética têm o mesmo número de páginas, abordam as mesmas unidades de estudo e exercícios, com a mesma distribuição de páginas para cada conteúdo no livro, havendo apenas variações na ortografia de palavras e na representação de unidades de medida e do sistema monetário. Esta é a principal alteração observada nas duas edições, pois até 31 de outubro de 1942 a moeda brasileira era denominada réis, e a partir de $1^{\circ}$ de novembro de 1942 entrou em vigor o cruzeiro $(\mathrm{Cr} \$)$.

\section{As curiosidades matemáticas nas aritméticas da série Ordem e Progresso}

A Primeira Aritmética da série Ordem e Progresso enfatiza o estudo da numeração até 100 . O estudo dos números de 0 a 100 inicia-se com a numeração de 0 a 10 , explorando o significado de quantidades até 10 e as operações de adição e subtração. Depois, ampliase o estudo com os números até 20 e até 100, envolvendo a escrita em ordem crescente e decrescente dos números e as operações com números naturais. Na introdução dos números até 10 se observa que o autor emprega o método de ensino intuitivo ${ }^{7}$, mas no restante da obra predominam propostas de ensino marcadas pela tradição pedagógica da memorização (VALENTE; PINHEIRO, 2015).

Na edição da Primeira Aritmética se observa que o estudo da numeração até 10 é feito por uma sistematização que associa quantidades de animais ou de objetos à

\footnotetext{
${ }^{6}$ Instituto pedagógico-teológico que atuou na formação de pastores e de professores paroquiais para IELB. ${ }^{7}$ Método de ensino que surgiu na Alemanha no final do século XVIII e divulgado pelos discípulos de Pestalozzi no decorrer do século XIX, na Europa e nos Estados Unidos. No Brasil, fez parte das propostas de reformulação da instrução pública no final do Império, sendo Rui Barbosa responsável por sistematizar os princípios do método de ensino intuitivo em seus pareceres e por traduzir o manual, Lições de Coisas, de Calkins. No método intuitivo, a escola deveria ensinar coisas vinculadas à vida, utilizar os objetos como suporte didático e os sentidos para produção de ideias, iniciando do concreto e ascendendo à abstração.
} 
representação simbólica do número, seguida de cálculos que envolvem as operações de adição ou subtração. A Figura 1 ilustra a proposta do autor para estudo do número 3:

Figura 1: O número 3

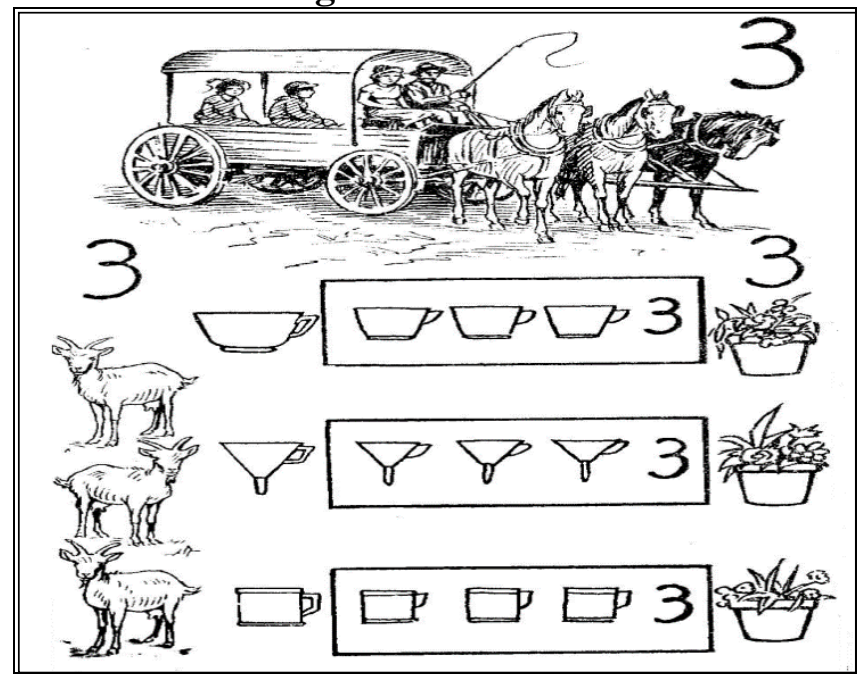

Fonte: Strelow (193-, p. 3)

A proposta observada na Figura 1 desenvolve a construção do conceito de número de forma intuitiva, associando o número 3 com a representação de 3 animais ou 3 objetos, pertencentes ao contexto sociocultural dos alunos das escolas paroquiais luteranas gaúchas. O fragmento traz 3 cavalos puxando uma carroça, porém, esta é ocupada por 4 pessoas. Talvez o autor pudesse ter feito a representação de 3 pessoas na carroça para também associar ao estudo do número 3. Destaca-se que, para o estudo dos números até 10, o autor do livro usa a estratégia de relacionar, de forma padronizada, a ideia do número com a quantidade de cavalos puxando uma carroça. Para o estudo do zero, o autor usa a representação de uma carroça com a ausência de cavalos (0), conforme mostrado na Figura 2:

Figura 2: O número 0

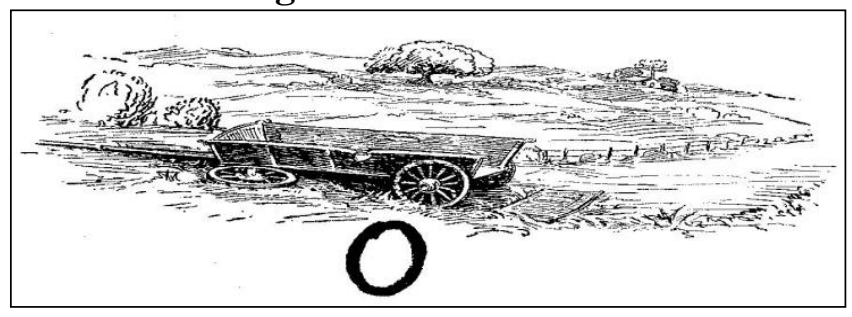

Fonte: Strelow (193-, p. 20) 
Na investigação realizada, observou-se que o autor da Primeira Aritmética propõe três blocos de contas orais, para cada dia da semana, de segunda-feira a sábado ${ }^{8}$, conforme exemplo descrito no Quadro 1:

Quadro 1: Contas orais de segunda-feira a sábado Por meio dum auxiliar que seja um aluno adiantado. SEXTAS Cada criança um quadro de cor!

\begin{tabular}{c|c|c|c|c|c|c}
\hline 1. & 2. & 3. & 4. & 5. & 6. & 7. \\
$11-1$ & $20-10$ & $11-2$ & $12-3$ & $13-4$ & $14-5$ & $15-6$ \\
$12-2$ & $19-9$ & $11-3$ & $12-4$ & $13-5$ & $14-6$ & $15-7$ \\
$13-3$ & $18-8$ & $11-4$ & $12-5$ & $13-6$ & $14-7$ & $15-8$ \\
$14-4$ & $17-7$ & $11-5$ & $12-6$ & $13-7$ & $14-8$ & $15-9$ \\
$15-5$ & $16-6$ & $11-6$ & $12-7$ & $13-8$ & $14-9$ & \\
$16-6$ & $15-5$ & $11-7$ & $12-8$ & $13-9$ & & $16-7$ \\
$17-7$ & $14-4$ & $11-8$ & $12-9$ & & $18-9$ & $16-8$ \\
$18-8$ & $13-3$ & $11-9$ & & $17-8$ & & $16-9$ \\
$19-9$ & $12-2$ & & & $17-9$ & & \\
$20-10$ & $11-1$ & & & & & \\
\hline
\end{tabular}

Fonte: Strelow (193-, p. 35)

O Quadro 1 mostra as contas sugeridas para sexta-feira no segundo bloco de contas orais, proposto na Primeira Aritmética. Estas contas envolvem a operação de subtração com números até 20 e deveriam ser realizadas oralmente com o auxílio de um aluno adiantado, talvez de uma série posterior nas escolas com classes multisseriadas ${ }^{9}$. O autor faz propostas semelhantes, para cada dia da semana, em três blocos: da página 22 até 26 (somente cálculos de adição e subtração com números até 10), da página 32 até 35 (somente cálculos de adição e subtração com números até 20) e da página 59 até 64 (cálculos de adição, subtração, multiplicação e divisão com números até 100). As propostas do autor orientam que as contas orais deveriam ser repetidas nas semanas posteriores, até se chegar ao próximo bloco de contas sugerido, observando-se o aumento gradativo do grau de dificuldade nas contas orais. Dessa forma, os alunos eram submetidos a um tirocínio de cálculos na escola, tanto escritos, quanto orais; verificandose propostas de ensino marcadas pela retórica e memorização (VALENTE; PINHEIRO, 2015).

\footnotetext{
${ }^{8}$ Nas escolas paroquiais luteranas gaúchas, a programação escolar cobria 6 dias da semana, com 4 horas diárias, perfazendo 24 horas semanais, geralmente no turno da manhã.

${ }^{9}$ A maioria das escolas paroquiais luteranas do RS era organizada de forma multisseriada, sendo que alunos de quatro ou cinco séries diferentes as frequentavam juntos, com um único professor. Essas turmas eram compostas de 20 a 40 alunos.
} 
Strelow (193-) também apresenta uma proposta para os alunos decorarem as tabuadas de multiplicar, conforme mostrado no Quadro 2:

Quadro 2: Como se decora as tabuadas de multiplicar

\begin{tabular}{|c|c|c|c|c|}
\hline \multicolumn{5}{|c|}{ Exemplo: A tabuada de 2.} \\
\hline 1) Pela ordem & 2) Pela ordem & 3) Salteando & 4) Salteando & 5) Salteando \\
\hline crescente & decrescente & crescente & decrescente & misto \\
\hline $1 \times 2=$ & $10 \times 2=$ & $1 \times 2=$ & $10 \times 2=$ & $1 \times 2=$ \\
\hline $2 \times 2=$ & $9 \times 2=$ & $3 \times 2=$ & $8 \times 2=$ & $10 \times 2=$ \\
\hline $3 \times 2=$ & $8 \times 2=$ & $5 \times 2=$ & $6 \times 2=$ & $2 \times 2=$ \\
\hline $4 \times 2=$ & $7 \times 2=$ & $7 \times 2=$ & $4 \times 2=$ & $9 \times 2=$ \\
\hline $5 \times 2=$ & $6 \times 2=$ & $9 \times 2=$ & $2 \times 2=$ & $3 \times 2=$ \\
\hline $6 \times 2=$ & $5 \times 2=$ & $2 \times 2=$ & $9 \times 2=$ & $8 \times 2=$ \\
\hline $7 \times 2=$ & $4 \times 2=$ & $4 \times 2=$ & $7 \times 2=$ & $4 \times 2=$ \\
\hline $8 \times 2=$ & $3 \times 2=$ & $6 \times 2=$ & $5 \times 2=$ & $7 \times 2=$ \\
\hline $9 \times 2=$ & $2 \times 2=$ & $8 \times 2=$ & $3 \times 2=$ & $5 \times 2=$ \\
\hline $10 \times 2=$ & $1 \times 2=$ & $10 \times 2=$ & $1 \times 2=$ & $6 \times 2=$ \\
\hline
\end{tabular}

Fonte: Strelow (193-, p. 50)

O Quadro 2 ilustra a proposta do autor para se decorar as tabuadas de multiplicar, exemplificando com a tabuada de 2 e indicando os seguintes passos: $1^{\circ}$ pela ordem crescente, $2^{\circ}$ pela ordem decrescente, $3^{\circ}$ salteando crescente (primeiro os fatores ímpares e depois os fatores pares, em ordem crescente), $4^{\circ}$ salteando decrescente (primeiro os fatores pares e depois os fatores ímpares, em ordem decrescente) e $5^{\circ}$ salteando misto (intercalando ordem crescente e ordem decrescente). Na página seguinte do livro, propõese a aplicação deste procedimento com as tabuadas de multiplicar de 3 até 10 , oralmente e por escrito. O exercício da pequena tabuada - tabuadas do 1 ao 10 - era frequente nos primeiros anos de escolarização e mostra a preocupação do autor em instrumentalizar os alunos das escolas paroquiais luteranas gaúchas para o cálculo mental e escrito. Essa aritmética também apresenta uma proposta de estudo para decorar as tabuadas de dividir de 2 até 10, de forma semelhante à proposta para decorar as tabuadas de multiplicar, ficando subentendida a ideia de que a multiplicação e a divisão são operações inversas. Novamente, observam-se propostas de ensino focadas na memorização dos conteúdos.

No final da Primeira Aritmética se encontram informações sobre unidades de medidas, como unidades de comprimento, capacidade, massa e tempo, sem, no entanto, preocupar-se com a simbologia, conforme se pode observar no Quadro 3: 
Quadro 3: Unidades de medidas

\begin{tabular}{ll|}
1 braça - quantos palmos? & $(10)$ \\
1 metro - quantos centímetros? & $(100)$ \\
1 litro - quantas garrafas? & $\left(1 \frac{1}{2}\right)$ \\
1 saco - quantas quartas? & $(8)$ \\
1 lata de querosene - quantas quartas? & $(2)$ \\
1 arroba - quantos quilos? & $(15)$ \\
1 quilo - quantas gramas? & $(1000)$ \\
1 saco de milho - quantos quilos? & $(60)$ \\
1 saco de feijão - quantos quilos? & $(60)$ \\
1 saco de arroz em casca - quantos quilos? & $(50)$ \\
1 saco de arroz sem casca - quantos quilos? & $(60)$ \\
1 ano - quantos meses? & 12 \\
1 ano - quantas semanas? & 52 \\
1 ano - quantos dias nas contas? & 360 \\
1 mês - quantos dias nas contas? & 30 \\
1 dúzia - quantas coisas? & 12
\end{tabular}

Fonte: Strelow (193-, p. 60-61)

O autor dessa aritmética usa a estratégia de tratar das unidades de medidas que faziam parte do contexto dos alunos das escolas luteranas, mas sem explorá-las. Chama atenção a referência feita aos períodos de tempo comerciais, como: 1 mês $=30$ dias e 1 ano $=360$ dias. As unidades de medida apresentadas no Quadro 3 eram empregadas em transações comerciais, realizadas através das operações de troca, compra e venda de produtos agrícolas nas regiões coloniais. As colônias alemãs do RS geralmente praticaram a policultura, destacando-se a produção de: “[...] mandioca, cana de açúcar, batata inglesa, feijão preto, milho, arroz, fumo, cevada, aveia, centeio, amendoim, linho, algodão e ervamate" (ROCHE, 1969, p. 270). Nesse contexto surgiu o artesanato rural, que se dividiu em dois ramos: “[...] o fornecimento de artigos necessários à vida local e a transformação dos produtos agrícolas para torná-los exportáveis. Destacaram-se ferreiros, serralheiros, funileiros, pedreiros, marceneiros, alfaiates, sapateiros, fábricas de azeite, curtumes, moinhos de farinha, alambiques" (ROCHE, 1969, p. 482).

As principais unidades de estudo da edição da Terceira Arithmetica são: frações decimais e sistema métrico; frações ordinárias; regra de três; porcentagem; porcentagem comercial; juros; razão e proporção; geometria prática. Essa aritmética é caracterizada por apresentar propostas de estudo mais sistematizadas dos conhecimentos matemáticos.

No Quadro 4, apresentam-se algumas relações entre as antigas medidas brasileiras e as medidas do sistema métrico, encontradas na Terceira Arithmetica: 
Quadro 4: Relação entre antigas medidas brasileiras e medidas do sistema métrico

Medidas de comprimento

1 légua $=50$ quadras

1 légua $=3000$ braças

1 vara $=1 \mathrm{~m} 1(1 \mathrm{me} 1 \mathrm{dm})$

1 légua $=6000$ varas

1 braça $=2 \mathrm{~m} 2(2 \mathrm{~m} \mathrm{e} 2 \mathrm{dm})$

1 légua $=30000$ palmos

1 palmo $=0 \mathrm{~m} 22(22 \mathrm{~cm})$

1 quadra $=60$ braças

1 quadra $=120$ varas

1 polegada $=0 \mathrm{~m} 0275(27 \mathrm{~mm}$ e 5 décimos do

1 quadra $=600$ palmos $\mathrm{mm})$

1 braça $=2$ varas

1 jarda $=0 \mathrm{~m} 914(914 \mathrm{~mm})$

1 braça $=10$ palmos

1 pé $=0 \mathrm{~m} 33(33 \mathrm{~cm})$

1 vara $=5$ palmos

Medidas de superfície

As medidas de superfície são quadrados cujos lados têm igual comprimento seja qual for a medida linear. As mais usadas são as seguintes:

1 braça quadrada $=2 \mathrm{~m} 20 \times 2 \mathrm{~m} 20=4 \mathrm{~m}^{2} 84$

1 quadra quadrada $=60$ bra $\times 60$ bra $=3600$ bra $^{2}$

$$
=132 \mathrm{~m} \times 132 \mathrm{~m}=17424 \mathrm{~m}^{2}
$$

A quarta de terra de milho $=50$ bra $\times 25$ bra $=1250$ bra $^{2}$

$$
=110 \mathrm{~m} \times 55 \mathrm{~m}=6050 \mathrm{~m}^{2}
$$

\section{Medidas de volume}

As medidas de volume são cubos cujas faces são quadrados iguais.

1 braça cúbica $=10 \mathrm{~m}^{3} 648$

1 vara cúbica $=1 \mathrm{~m}^{3} 331$

1 pé cúbico $=0 \mathrm{~m}^{3} 028094$

Fonte: Série Ordem e Progresso (193-, p. 28-29)

Apresentam-se, no Quadro 4, as antigas medidas brasileiras de comprimento, superfície e volume. As medidas de comprimento observadas são: a légua, a quadra, a braça, a vara, o palmo, a polegada, a jarda e o pé, relacionadas com a principal unidade de medida de comprimento, o metro $(\mathrm{m})$. As antigas medidas de superfície estão relacionadas como metro quadrado $\left(\mathrm{m}^{2}\right)$, sendo elas: a braça quadrada $\left(\mathrm{bra}^{2}\right)$, a quadra quadrada e a quarta de terra de milho. Ressalta-se que estas unidades de medida de superfície eram usadas com frequência, na primeira metade do século passado, para representação de áreas de terras nas regiões coloniais (UNSERE SCHULE, 1934). Aponta-se que o texto do livro sobre as medidas de superfície é redundante ao considerar que as medidas de superfície são quadrados cujos lados têm igual comprimento seja qual for a medida linear. Já as antigas medidas de volume apresentadas são: a braça cúbica, a vara cúbica e o pé cúbico, ambas relacionadas com o metro cúbico $\left(\mathrm{m}^{3}\right)$, principal unidade de medida de volume. Com a gradativa adoção das medidas do sistema métrico, a partir de 1960, as antigas medidas brasileiras passaram a ser menos utilizadas, observando-se o seu uso em situações muito específicas, como por exemplo, aparelhos de televisão e 
monitores de computador, que costumam ser vendidos com medidas da diagonal em polegadas.

Verificou-se que a terceira unidade de estudo dessa aritmética aborda a regra de três simples direta, propondo inicialmente, de forma oral, a dedução da unidade para a multiplicidade, a dedução da multiplicidade para a unidade e a dedução da multiplicidade para a multiplicidade. Em seguida, propõe-se a regra de três simples direta por escrito com problemas sobre números inteiros, frações ordinárias e frações decimais. Conclui-se o estudo com a regra de três simples inversa e a regra de três composta. No Quadro 5, apresentam-se alguns problemas propostos para o estudo da regra de três simples direta, oralmente:

Quadro 5: Regra de três simples direta oralmente

a) Dedução da unidade para a multiplicidade:

1) 1 par de tamancos custa $2 \$ 500$. Calcular o preço de $3,5,6,9,10$ pares.

2) $1 / 2 \mathrm{~m}$ de seda custa $4 \$ 500$. Calcular o preço de $3,6,1 \frac{1}{2}, 8 \mathrm{~m}$.

3) $1 \mathrm{~kg}$ de batatas custa 400 réis. Calcular o preço de $5,10,20 \mathrm{~kg}, 1$ saco.

b) Dedução da multiplicidade para a unidade:

1) Um saco de feijão de $60 \mathrm{~kg}$ custa $24 \$ 000$. Quanto custa $1 \mathrm{~kg}$ ?

2) Um cavalo come em uma semana $171 / 2 \mathrm{~kg}$ de milho. Quanto por dia?

3) Um engenho de arroz descasca em 12 horas 100 sacos de arroz. Quanto por hora?

c) Dedução da multiplicidade para a multiplicidade:

1) $2 \mathrm{~m}$ de fazenda custam $5 \$ 000$.

Ex.: $2 \mathrm{~m}----5 \$ 000$

$4 \mathrm{~m}$ de fazenda custam .....

$1 \mathrm{~m}----5 \$ \div 2$

$8 \mathrm{~m}$ de fazenda custam .....

$4 \mathrm{~m}----5 \$ \div 2 \times 4$

$10 \mathrm{~m}$ de fazenda custam .....

$20 \mathrm{~m}$ de fazenda custam .......

$$
\frac{5 \times 4}{2}=10 \$ 000
$$

2) Uma arroba de fumo custa $52 \$ 500$. Quanto custam $30 \mathrm{~kg}, 60 \mathrm{~kg}, 90 \mathrm{~kg}$ ?

3) 6 laranjas de umbigos custam $\$ 500$. Quanto custam 12, 3, 18, 24, 30 laranjas de umbigos?

Fonte: Série Ordem e Progresso (193-, p. 69-71)

Verificou-se que o estudo da regra de três simples direta é introduzido por atividades propostas para serem resolvidas oralmente, sem qualquer sistematização do conteúdo. São exercícios e problemas contextualizados com práticas socioculturais das comunidades em que as escolas paroquiais luteranas gaúchas estavam inseridas e que estão relacionados com operações comerciais e unidades dos sistemas de medidas. As 29 situações propostas nessa aritmética envolvem compra e venda de produtos para alimentação e vestuário, consumo de alimentos, gastos familiares mensais (aluguel), produções agrícolas, salário de trabalhadores e tempo de trabalho em obras. 
Destaca-se que o pensamento proporcional é desenvolvido pela regra da dedução (SILVA, 2015), com a dedução da unidade para a multiplicidade por meio de uma multiplicação, da redução da multiplicidade para a unidade através de uma divisão e da dedução da multiplicidade para a multiplicidade com o emprego das operações de divisão e multiplicação, respectivamente, conforme observado no Quadro 5. No último caso, sugere-se a dedução da multiplicidade conhecida para a unidade e da unidade para a multiplicidade desconhecida, valendo-se da divisão e da multiplicação como operações inversas, conforme o exemplo apresentado no exercício 1. Nos problemas propostos, verifica-se também o emprego de frações ordinárias ou números mistos na representação de quantidades não inteiras. Destaca-se que toda proposta de estudo da regra de três simples e da regra de três composta é feita pela regra da dedução, sendo que o estudo da teoria das proporções, na Terceira Arithmetica, acontece somente após o estudo da porcentagem e dos juros simples.

O Quadro 6 mostra o estudo do volume de um tronco de cone, observado na Terceira Arithmetica:

Quadro 6 : Volume de um tronco de cone

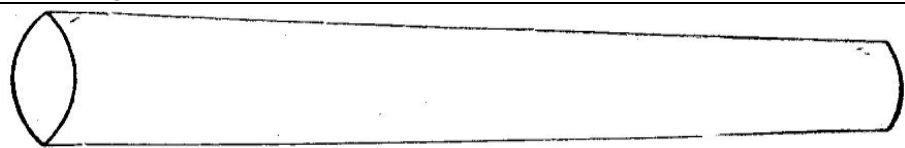

Para calcular o volume de um tronco de cone é preciso fazer um produto com as seguintes dimensões: O quadrado da metade da soma do raio maior e do menor multiplicado por Pi e pelo comprimento.

Ex.: Quer-se avaliar o volume de um tronco que tem $4 \mathrm{~m}$ de comprimento e cujo raio maior é $40 \mathrm{~cm}$ e o menor $30 \mathrm{~cm}$.

$40+30=70 \div 2=35$

$35 \times 35 \times 3,1416 \times 400=1 \mathrm{~m}^{3} 539384$

Fonte: Série Ordem e Progresso (193-, p. 140)

O excerto mostrado no Quadro 6 traz um procedimento de cálculo para o volume de um tronco de cone que resulta num valor aproximado do volume real do tronco com as dimensões citadas. Enquanto que o livro apresenta como resposta o valor aproximado de $1,539384 \mathrm{~m}^{3}$, o valor mais exato seria $1,549852 \mathrm{~m}^{3}$. Observa-se que a proposta do livro é determinar o volume do tronco de cone de uma forma prática e aproximada, sem uso de relações algébricas, possibilitando que o aluno aplique este conhecimento em situações concretas na colônia, especialmente no cálculo de volume de madeira. De acordo com 
Rambo (1994), o trabalho com madeira nas colônias só podia ser confiável com o domínio dos rudimentos do cálculo volumétrico nas suas mais diversas formas. Acrescenta-se que:

A cubagem da madeira é uma prática presente na vida das/os trabalhadoras/es rurais, consistindo no cálculo de quantos cúbicos tem numa árvore, no mato ou numa carga de caminhão. É utilizada para avaliar a quantia necessária de árvores que devem ser abatidas para serem transformadas em lenha, em tábuas para a construção de casas ou abrigos de animais, nos projetos de reflorestamento, na compra e venda de áreas arborizadas e nas negociações que a gente faz com os homens das serrarias (KNIJNIK, 1996, p. 52).

Outra curiosidade, observada na Terceira Arithmetica, relaciona a determinação da raiz quadrada envolvendo a geometria e a álgebra, conforme descrição no Quadro 7:

Quadro 7: Determinação do número quadrado e da raiz quadrada

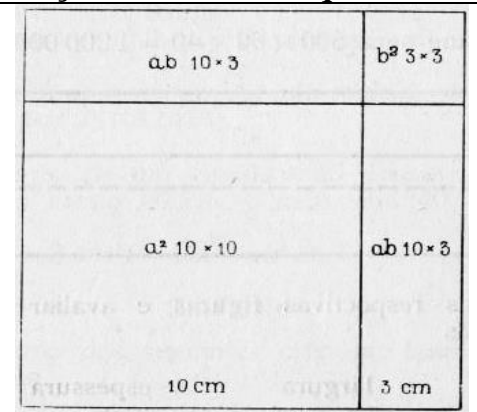

Número quadrado é o produto de um número multiplicado por si mesmo; e o número chama-se raiz quadrada.

Ex.: 4 × $4=16$.

4 é a raiz quadrada e 16 é o número quadrado.

Assim temos:

Raiz quadrada $\quad 1,2,3,4,5,6,7,8,9$.

Número quadrado $1,4,9,16,25,36,49,64,81$.

O quadrado de um número composto de dezenas e unidades consta de três partes:

Por exemplo: 13 x $13=169$

$1^{\circ}$ do quadrado das dezenas,

$2^{\circ}$ do dobro do produto das dezenas pelas unidades,

$3^{\circ}$ do quadrado das unidades.

O quadrado da dezena é

$10 \times 10=100$

O dobro da dezena pela unidade é

$2 \times 10 \times 3=60$

O quadrado das unidades é

$3 \times 3=9$

$13 \times 13=169$

Para extrair a raiz quadrada de um número, divide-se este em classes de dois algarismos, começando-se da direita para a esquerda, podendo a última classe constar de um só algarismo: 529.

As raízes das classes formadas tomam as designações a, b, c, etc...

Em seguida procura-se o maior quadrado contido na $1^{\mathrm{a}}$ classe da esquerda:

$\mathrm{a} \mathrm{b}$

$5.29=2$ 


\section{$\frac{4}{1}$}

O número formado do resto e do $1^{\mathrm{o}}$ número da $2^{\mathrm{a}}$ classe dividido por $2 \mathrm{a}$, dará $\mathrm{b}$ :

a b

$$
\begin{aligned}
& 5.29=23 \\
& (2 \mathrm{a}=2 \times 2) \frac{4}{12} \div 4 \\
& 12
\end{aligned}
$$

Do resto, se houver, e do último algarismo da $2^{\mathrm{a}}$ classe subtrai-se b quadrado: a b

$$
5.29=23
$$

$$
\underline{4}
$$

$$
\begin{aligned}
& \underline{12} \\
& \text { (b quadrado }=3 \times 3) \quad 9 \\
& \underline{9} \\
& \mathrm{a}=\text { duas dezenas }=20 \text { unidades } \\
& \mathrm{b}=3 \text { unidades }
\end{aligned}
$$

$\mathrm{O}$ quadrado das dezenas $\quad=20 \times 20=400$

O dobro do produto das dezenas pelas unidades $=2 \times 20 \times 3=120$

O quadrado das unidades $\quad=\quad 3 \times 3=\frac{9}{529}$

Fonte: Série Ordem e Progresso (193-, p. 140-142)

No Quadro 7, apresenta-se uma relação entre número quadrado e raiz quadrada, associando esta ideia com a representação geométrica de um quadrado. O estudo é ilustrado com um exemplo para determinação do quadrado do número composto 13 . A proposta consiste em fazer sua decomposição em dezena e unidades $(a=10$ e $b=3)$ e sua representação com um quadrado maior $\left(\mathrm{a}^{2}\right)$, dois retângulos (2ab) e um quadrado menor $\left(b^{2}\right)$. Observa-se o quadrado da dezena $\left(\mathrm{a}^{2}=10^{2}=10 \times 10=100\right)$, o dobro da dezena pelas unidades $(2 \mathrm{ab}=2 \times 10 \times 3=60)$ e o quadrado das unidades $\left(b^{2}=3^{2}=3 \times 3=9\right)$. Logo, 169 é o quadrado do número 13 e 13 é a raiz quadrada de 169. De acordo com o excerto, essas relações são válidas para o quadrado de números compostos de dezenas e unidades. Tomando-se como exemplo o quadrado de 23, tem-se:

$23=20+3$, ou seja, $a=20$ e $b=3$.

- o quadrado das dezenas: $\mathrm{a}^{2}=20^{2}=20 \times 20=400$;

- o dobro das dezenas pelas unidades: $2 \mathrm{ab}=2 \times 20 \times 3=120$;

- o quadrado das unidades: $b^{2}=3^{2}=3 \times 3=9$.

Portanto, $23^{2}=(20+3)^{2}=20^{2}+2 \times 20 \times 3+3^{2}=400+120+9=529$, ou seja, 23 é a raiz quadrada do número quadrado 529. 
A representação geométrica de um número quadrado traz implicitamente a ideia de um produto notável, $(\mathrm{a}+\mathrm{b})^{2}=\mathrm{a}^{2}+2 \mathrm{ab}+\mathrm{b}^{2}$, relacionando conhecimentos de aritmética, geometria e álgebra.

O fragmento apresentado no Quadro 7 também apresenta um algoritmo e procedimento para extração da raiz quadrada de um número, exemplificando-os com a determinação da raiz quadrada de 529. Propõe-se, inicialmente, a divisão deste número em classes de dois algarismos, começando-se da direita para a esquerda. Em seguida, aplica-se um procedimento de cálculo que está fundamentado no desenvolvimento do produto notável $(a+b)^{2}$.

A análise das aritméticas da série Ordem e Progresso, direcionadas para as escolas paroquiais luteranas gaúchas, na primeira metade do século $\mathrm{XX}$, permitiu um adentramento na cultura escolar num lugar e num tempo determinados, identificando-se curiosidades matemáticas nesse contexto, conforme a discussão realizada e considerações finais apresentadas na sequência deste artigo.

\section{Considerações finais}

Partindo do referencial teórico-metodológico da história cultural, investigaram-se curiosidades matemáticas encontradas nas edições da Primeira Aritmética e da Terceira Arithmetica, ambas da série Ordem e Progresso, editadas pela IELB, através da Casa Publicadora Concórdia, na década de 1930, para suas escolas paroquiais no RS. Nesse contexto missionário e de formação geral, a Igreja Luterana editou livros didáticos de acordo com seus princípios morais e educacionais, adaptando-se ao processo de nacionalização do ensino em curso.

Na análise da Primeira Aritmética, identificou-se que o autor propôs a construção do significado de número pelo método de ensino intuitivo, evidenciando-se a estratégia padronizada de associar cada número até 10 com a quantidade de cavalos puxando uma carroça. Também se observaram propostas de ensino marcadas pela retórica e memorização, como blocos de contas orais para serem realizados em cada um dos seis dias de aula na semana, envolvendo as quatro operações elementares com números naturais até 100, além de procedimentos para os alunos decorarem as tabuadas de multiplicar e dividir. No final dessa aritmética, o autor apresenta informações sobre unidades de comprimento, capacidade, massa e tempo, as quais faziam parte do contexto sociocultural dos alunos das escolas paroquiais luteranas gaúchas. 
Na edição da Terceira Arithmetica chamaram atenção as relações entre as antigas medidas brasileiras e as medidas do sistema métrico; a proposta de estudo da regra de três pela regra da dedução e não pela teoria das proporções, como geralmente é proposto nos livros didáticos atuais; o cálculo do volume de um tronco de cone de forma prática e aproximada, sem uso de relações algébricas; a determinação de números quadrados e da raiz quadrada de um número de maneira articulada com a geometria e a álgebra.

Mesmo que essas aritméticas da série Ordem e Progresso tenham sido editadas num período marcado pelo início do movimento da Escola Nova no Brasil, e que algumas curiosidades matemáticas estejam alicerçadas no método de ensino intuitivo, as mesmas ainda refletem a tradição pedagógica da memorização. Isto está associado ao fato de que o ensino da Matemática nas escolas paroquiais luteranas gaúchas do século passado foi marcado pelo desenvolvimento de habilidades para o cálculo mental e escrito, de forma prática e contextualizada, para que os futuros colonos fizessem a correta administração do seu orçamento familiar e o gerenciamento da sua propriedade rural.

\section{REFERÊNCIAS}

ARENDT, I. C. Representações de Germanidade, Escola e Professor no Allgemeine Lehrerzeitung für Rio Grande do Sul [Jornal Geral para o Professor no Rio

Grande do Sul]. 2005. 292 f. Tese (Doutorado em História) - Universidade do Vale do Rio dos Sinos, São Leopoldo, 13 abr. 2005.

BARROS, J. A. História cultural: um panorama teórico e historiográfico. Textos de História, v. 11, n. 1/2, p. 145-171, 2003.

BRITTO, S. L. M. O ensino da aritmética nas escolas paroquiais católicas e no Ginásio Conceição, sob a ótica dos jesuítas nos séculos XIX e XX. 2016. 464 f. Tese (Doutorado em Ensino de Ciências e Matemática) - Universidade Luterana do Brasil, Canoas, 09 ago. 2016.

CHARTIER, R. A História cultural: entre práticas e representações. Lisboa: Difel, 1990. $244 \mathrm{p}$.

KNIJNIK, G. Exclusão e resistência: educação matemática e legitimidade cultural. Porto Alegre: Artes Médicas, 1996. 139 p.

KREUTZ, L. Livros escolares e imprensa educacional periódica dos imigrantes alemães no Rio Grande do Sul, Brasil 1870-1939. Revista Educação em Questão, Natal, v. 31, n. 17, p. 24-52, jan./abr. 2008.

KREUTZ, L. Material didático e currículo na escola teuto-brasileira. São Leopoldo: Ed. UNISINOS, 1994. 
KREUTZ, L. O professor paroquial: magistério e imigração alemã. Porto Alegre: Ed. da UFRGS; Caxias do Sul: EDUCS, 1991.

KREUTZ, L.; ARENDT, I. C. (Org.). Livros escolares das escolas de imigração alemã no Brasil (1832-1940). Acervo documental e de pesquisa, Biblioteca UNISINOS. São Leopoldo, 2007. 3 CD-ROM.

KUHN, M. C. O ensino da matemática nas escolas evangélicas luteranas do Rio Grande do Sul durante a primeira metade do século XX. 2015. 466 f. Tese (Doutorado em Ensino de Ciências e Matemática) - Universidade Luterana do Brasil, Canoas, 09 jul. 2015.

LEMKE, M. D. Os princípios da educação cristã luterana e a gestão de escolas confessionárias no contexto das ideias pedagógicas no sul do Brasil (1824 - 1997). Canoas: Ed. ULBRA, 2001. 248 p.

MAURO, S. Uma história da matemática escolar desenvolvida por comunidades de origem alemã no Rio Grande do Sul no final do século XIX e início do século XX. 2005. 251 f. Tese (Doutorado em Educação Matemática) - Universidade Estadual Paulista, Rio Claro, 03 maio 2005.

RAMBO, A B. A escola comunitária teuto-brasileira católica. São Leopoldo: Ed. UNISINOS, 1994. 208 p.

RAMBO, A B. A escola comunitária teuto-brasileira católica: a associação de professores e a escola normal. São Leopoldo: Ed. UNISINOS, 1996. 243 p.

ROCHE, J. A Colonização Alemã e o Rio Grande do Sul. Porto Alegre: Editora Globo, 1969. v. 1 e v. 2.806 p.

SÉRIE Ordem e Progresso: Terceira Arithmetica. Porto Alegre: Casa Publicadora Concórdia, [193-]. 143 p.

SILVA, C. M. S. A Regra de Ouro nos Livros Didáticos para Escolas AlemãsBrasileiras. Acta Scientiae, Canoas, v. 17, Ed. Especial, p. 41-59, 2015.

STRELOW, F. Série Ordem e Progresso: Primeira Aritmética. Porto Alegre: Casa Publicadora Concórdia, [193-]. 64 p.

UNSERE SCHULE. Porto Alegre: Casa Publicadora Concórdia, 1933-1935.

VALENTE, W. R.; PINHEIRO, N. V. L. Chega de decorar a tabuada! - As cartas de Parker e a árvore do cálculo na ruptura de uma tradição. Educação Matemática em Revista - RS, Canoas, v. 1, n. 16, p. 22-37, 2015.

WANDERER, F. Escola e Matemática Escolar: mecanismos de regulação sobre sujeitos escolares de uma localidade rural de colonização alemã no Rio Grande do Sul. 2007. 228 f. Tese (Doutorado em Educação) - Universidade do Vale do Rio dos Sinos, São Leopoldo, 2007. 
WARTH, C. H. Crônicas da Igreja: Fatos Históricos da Igreja Evangélica Luterana do Brasil (1900 a 1974). Porto Alegre: Concórdia, 1979.

WEIDUSCHADT, P. A revista "O Pequeno Luterano" e a formação educativa religiosa luterana no contexto pomerano em Pelotas - RS (1931-1966). 2012. $273 \mathrm{f}$. Tese (Doutorado em Educação) - Universidade do Vale do Rio dos Sinos, São Leopoldo, 11 jan. 2012.

WEIDUSCHADT, P. O Sínodo de Missouri e a educação pomerana em Pelotas e São Lourenço do Sul nas primeiras décadas do século XX: identidade e cultura escolar. 2007. 253 f. Dissertação (Mestrado em Educação) - Universidade Federal de Pelotas, Pelotas, 2007.

\section{Como referenciar este artigo}

KUHN, Malcus Cassiano.; BAYER, Arno. Curiosidades matemáticas nas aritméticas da série Ordem e Progresso. Revista Ibero-Americana de Estudos em Educação, Araraquara, v. 12, n. 4, p. 2088-2107, out./dez. 2017. Disponível em: <http://dx.doi.org/10.21723/riaee.v12.n4.out./dez.2017.8759>. E-ISSN: 1982-5587.

Submetido em: 05/07/2016

Aceite em: 01/07/2017 